\title{
Resveratrol induces cell cycle arrest in human gastric cancer MGC803 cells via the PTEN-regulated PI3K/Akt signaling pathway
}

\author{
XIAOPING JING ${ }^{1 *}$, WEIWEI CHENG ${ }^{1 *}$, SHIYING WANG ${ }^{2}$, PIN LI $^{1}$ and LI HE ${ }^{1}$ \\ ${ }^{1}$ Department of Traditional Chinese Medicine, Shanghai Children's Hospital, \\ Shanghai Jiao Tong University, Shanghai 200040; ${ }^{2}$ Department of General Surgery, \\ Putuo Hospital of Shanghai University of Traditional Chinese Medicine, Shanghai 200062, P.R. China
}

Received July 19, 2015; Accepted October 1, 2015

DOI: $10.3892 /$ or.2015.4384

\begin{abstract}
Resveratrol is a polyphenolic compound that is extracted from Polygonum cuspidatum and is used in traditional Chinese medicine. Previous data have shown that resveratrol inhibits the growth of human gastric cancer. MTT [3-(4,5-dimethylthiazol-2-yl)-2,5-diphenyl tetrazolium bromide] and trypan blue assays showed that resveratrol significantly decreased the survival rate of MGC803 cells in a concentration-and time-dependent manner.Ourflow cytometric analysis showed that resveratrol treatment arrested the cells at the G0/G1 phase of the cell cycle. Furthermore, western blotting demonstrated that resveratrol decreased the protein expression of phospho-glycogen synthase kinase $3 \beta$ (p-GSK3 $\beta$ ), cyclin D1, phospho-phosphatase and tensin homologue ( $p-P T E N)$, phospho-phosphatidylinositol 3'-OH kinase (p-PI3K), and phospho-protein kinase $\mathrm{B}$ (p-PKB/Akt). We also found that resveratrol inhibited the progression of the cell cycle in MGC803 cells by repressing p-PI3K and p-Akt expression. Meanwhile, resveratrol did not decrease the phosphorylation level of Akt when the PTEN gene expression was knocked down by an siRNA in the MGC803 cells. Taken together, these results suggest that resveratrol induced cell cycle arrest in human gastric cancer MGC803 cells by regulating the PTEN/ PI3K/Akt signaling pathway.
\end{abstract}

Correspondence to: Dr Li He, Department of Traditional Chinese Medicine, Children's Hospital of Shanghai, Children's Hospital Affiliated to Shanghai Jiao Tong University, 24 Lane, 1400 West Beijing Road, Shanghai 200040, P.R. China

E-mail: hel@shchildren.com.cn

${ }^{*}$ Contributed equally

Key words: MGC803 cells, cell cycle arrest, PTEN/PI3K/Akt signaling pathway, resveratrol

\section{Introduction}

Gastric cancer (GC) was found to be the fifth most common malignancy in 2012 (0.95 million cases, 6.8\% of all cancer cases) and was responsible for the third highest mortality rate $(0.72$ million deaths, $8.8 \%$ of the total $)$ worldwide. More than $70 \%$ of cases ( 0.67 million cases) occur in developing countries ( 0.45 million in men, 0.22 million in women), and $50 \%$ of the worldwide cases occur in Eastern Asia (mainly China) (1). In Southeastern Asia, 14.0 per 100,000 men and 9.8 per 100,000 women die of GC, and these mortality rates are 4.0-4.5 times higher than those in the United States and Europe (1). Currently, GC is primarily treated with surgery, chemotherapy and radiotherapy. Two recent and large randomized controlled trials (RCTs) showed that adjuvant chemotherapy reduced the recurrence rate and improved survival (2,3). Resveratrol (3,4,5-trihydroxystilbene) is a polyphenol compound that is extracted from Polygonum cuspidatum for use in traditional Chinese medicine; it has significant anti-bacterial, anti-inflammatory, anticancer, anti-hyperlipidemia, lipid peroxidation and anti-apoptotic effects (4-6). However, the mechanism of action of resveratrol in regards to the treatment and prevention of GC has not been determined in previous studies.

Cyclin D1 is an important protein related to the G0/G1 cell cycle checkpoint (7). Phospho-glycogen synthase kinase $3 \beta$ (p-GSK3 $\beta$ ) has been reported to regulate cyclin D1 expression (8). GSK3 $\beta$ is an important protein in the phosphatidylinositol 3'-OH kinase (PI3K)/protein kinase B (Akt) signaling pathway. Several studies have shown that PI3K/Akt signaling plays a pivotal role in the development and progression of cancer $(9,10)$. Phosphatase and tensin homolog (PTEN), a switch gene, can inhibit tumor cell growth by downregulating the protein expression of $\mathrm{p}-\mathrm{PI} 3 \mathrm{~K}$ and $\mathrm{p}$-Akt of the PI3K/Akt signaling pathway $(11,12)$. PTEN also regulates cell cycle arrest in the G1 phase by repressing the protein expression of p-PI3K and p-Akt $(13,14)$.

Therefore, we explored the effects of resveratrol on the proliferation of human gastric adenocarcinoma MGC803 cells and examined the underlying mechanisms of the involvement of resveratrol in the PTEN/PI3K/Akt pathway. 


\section{Materials and methods}

Cell culture. The human gastric adenocarcinoma cell line MGC803 was obtained from the Cell Bank of the Chinese Academic of Science and was maintained in RPMI-1640 medium supplemented with $10 \%$ fetal bovine serum (both from Invitrogen Life Technologies, Carlsbad, CA, USA), $100 \mathrm{U} / \mathrm{ml}$ penicillin and $100 \mu \mathrm{g} / \mathrm{ml}$ streptomycin at $37^{\circ} \mathrm{C}$ in a humidified atmosphere of $95 \%$ and $5 \% \mathrm{CO}_{2}$.

Reagents. Resveratrol with a purity exceeding 98\% was purchased from Sigma-Aldrich (St. Louis, MO, USA). Its structure is shown in Fig. 1. It was dissolved in DMSO at the desired concentrations and diluted in media at a maximal concentration of $0.1 \%$. The concentration of DMSO in the controls was also $0.1 \%$.

Cell proliferation assay. The effect of resveratrol on the cell viability was evaluated using the (3-(4,5-dimethylthiazol2-yl)-2,5-diphenyl tetrazolium bromide) (MTT) (Promega Corporation, Madison, WI, USA). After 24 and 48 h of exposure to different concentrations of resveratrol, $10 \mu \mathrm{l}$ of MTT $(5 \mathrm{mg} / \mathrm{ml})$ was added to each well, and the cells were incubated for $4 \mathrm{~h}$. The medium was then removed, and $150 \mu \mathrm{l}$ of DMSO was added to each well. The absorbance was recorded at $570 \mathrm{~nm}$ in a microplate reader, and the inhibition ratio (I\%) was calculated using the following equation: $\mathrm{I} \%=[\mathrm{A} 570$ (control) - A570 (treated)]/A570 (control) x 100.

Cell viability assay. After removing the cell culture medium, the MGC803 cells were gently rinsed twice with phosphate-buffered saline (PBS). To determine the effect of resveratrol on cell viability, MGC803 cells were cultured in a 24-well plate at $\sim 1 \times 10^{5}$ cells/well with serum-free medium and were allowed to adapt for $24 \mathrm{~h}$. For the drug treatment group, the culture medium was then replaced with medium containing the appropriate concentration of resveratrol $(50,100$ and $200 \mu \mathrm{mol} / \mathrm{l})$. The control was incubated in serum-free medium alone. The cells were then incubated for $24 \mathrm{~h}$. At the end of the test, the cells were stained with trypan blue and counted. All assays were performed at least three times (15).

Flow cytometric analysis of cell cycle arrest. To examine cell cycle arrest, MGC803 cells $\left(1 \times 10^{6}\right)$ were cultured in $60-\mathrm{mm}$ Petri dishes and incubated for $24 \mathrm{~h}$. The cells were then harvested, washed with PBS, resuspended in $250 \mu \mathrm{l}$ of PBS, and fixed in $750 \mu \mathrm{l}$ of $100 \%$ ethanol at $4^{\circ} \mathrm{C}$. After an overnight incubation, the cell pellets were collected by centrifugation, resuspended in $1 \mathrm{ml}$ of $1 \mathrm{X}$ Annexin $\mathrm{V}$ binding buffer (BD Biosciences, San Jose, CA, USA) at a concentration of $1 \times 10^{6}$ cells $/ \mathrm{ml}$ and transferred to $100 \mu \mathrm{l}$ of solution $\left(1 \times 10^{5}\right.$ cells $)$ in a $5-\mathrm{ml}$ culture tube. Subsequently, $5 \mu \mathrm{l}$ of FITC Annexin V and $5 \mu \mathrm{l}$ of propidium iodide (PI) were added to the tube, and the cells were gently vortexed and incubated for $15 \mathrm{~min}$ at room temperature $\left(\mathrm{RT}, 25^{\circ} \mathrm{C}\right)$ in the dark. Thereafter, $400 \mu \mathrm{l}$ of $1 \mathrm{X}$ binding buffer was added to the tube. The fluorescence emitted by the PI-DNA complex was quantified after the excitation of the fluorescent dye by FACScan cytometry (BD Biosciences). The fraction of cells in each cell cycle stage was quantitated with ModFit LT for Mac 3.0 software (BD Biosciences).

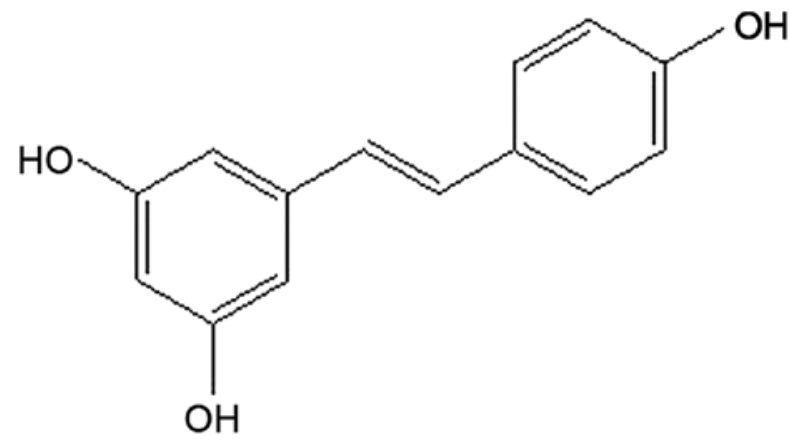

Figure 1. Chemical structure of resveratrol. $\mathrm{C}_{14} \mathrm{H}_{12} \mathrm{O}_{3}$, molecular formula; 228.25, average molecular mass.

RNA interference assay. PTEN-siRNA was purchased from GeneChem Biotech Ltd. (Shanghai, China). One day before the transfection, the MGC803 cells were allowed to adhere and were counted. The cell concentration was adjusted to $2 \times 10^{6} / \mathrm{ml}$. The cells were then grown in 6-well plates in $2.5 \mathrm{ml}$ of antibiotic-free cell culture medium. For each well to be transfected, PTEN-siRNA-Lipofectamine ${ }^{\text {TM }}$ RNAiMAX complexes were prepared as follows. i) PTEN-siRNA plasmid $\left(150\right.$ pmol) was diluted in $250 \mu \mathrm{l}$ of Opti-MEM ${ }^{\circledR}$ I Reduced Serum Medium (Gibco, Grand Island, NY, USA) and the solution was gently mixed. ii) Lipofectamine ${ }^{\mathrm{TM}}$ RNAiMAX (Invitrogen Life Technologies) was gently mixed and $12 \mu \mathrm{l}$ of the reagent was then diluted in $250 \mu 1$ of Opti-MEM ${ }^{\circledR} \mathrm{I}$ Reduced Serum Medium. The solution was gently mixed. iii) The diluted PTEN-siRNA plasmid was added to the diluted Lipofectamine ${ }^{\mathrm{TM}}$ RNAiMAX. The solution was gently mixed and incubated for $15 \mathrm{~min}$ at RT in the dark. The PTEN-siRNA-Lipofectamine ${ }^{\mathrm{TM}}$ RNAiMAX complexes were then added to each well containing cells. The final volume of these solutions was $3 \mathrm{ml}$, and the final concentration of RNA was $50 \mathrm{nM}$. The plates were gently mixed by rocking the plate back and forth. Finally, the cells were incubated for $24 \mathrm{~h}$ at $37^{\circ} \mathrm{C}$ in a humidified atmosphere containing $5 \% \mathrm{CO}_{2}$ and $95 \%$ air.

Western blot analysis. The cell pellets were resuspended in lysis buffer (Beyotime, Haimen, China) and lysed on ice for $30 \mathrm{~min}$. After centrifugation for $30 \mathrm{~min}$, the supernatant was collected, and the protein content of the supernatant was measured using a bicinchoninic acid (BCA) protein assay kit (Beyotime). The protein lysates $(20 \mu \mathrm{l})$ were separated by electrophoresis on a $12 \%$ SDS-polyacrylamide gel and transferred to a polyvinylidene fluoride (PVDF) membrane (Millipore, Billerica, MA, USA). The membranes were subsequently blocked with $5 \%$ bovine serum albumin for $2 \mathrm{~h}$. The membranes were then probed with specific primary antibodies against PI3K (rabbit monoclonal, 1:1,000; Cell Signaling Technology, Inc., Danvers, MA, USA), p-PI3K $(1: 1,000)$, Akt $(1: 1,000)$, p-Akt (Ser-473) $(1: 1,000)$, PTEN $(1: 1,000)$ and p-PTEN $(1: 1,000)$ overnight at $4^{\circ} \mathrm{C}$. All primary antibodies were purchased from Cell Signaling Technology Inc. Rabbit monoclonal anti-human p-GSK3 $\beta(1: 1,000)$ and GSK3 $\beta(1: 5,000)$ antibodies were purchased from Abcam (Cambridge, UK). Anti-rabbit antibody was purchased from Cell Signaling Technology Inc. Anti-rabbit horseradish 

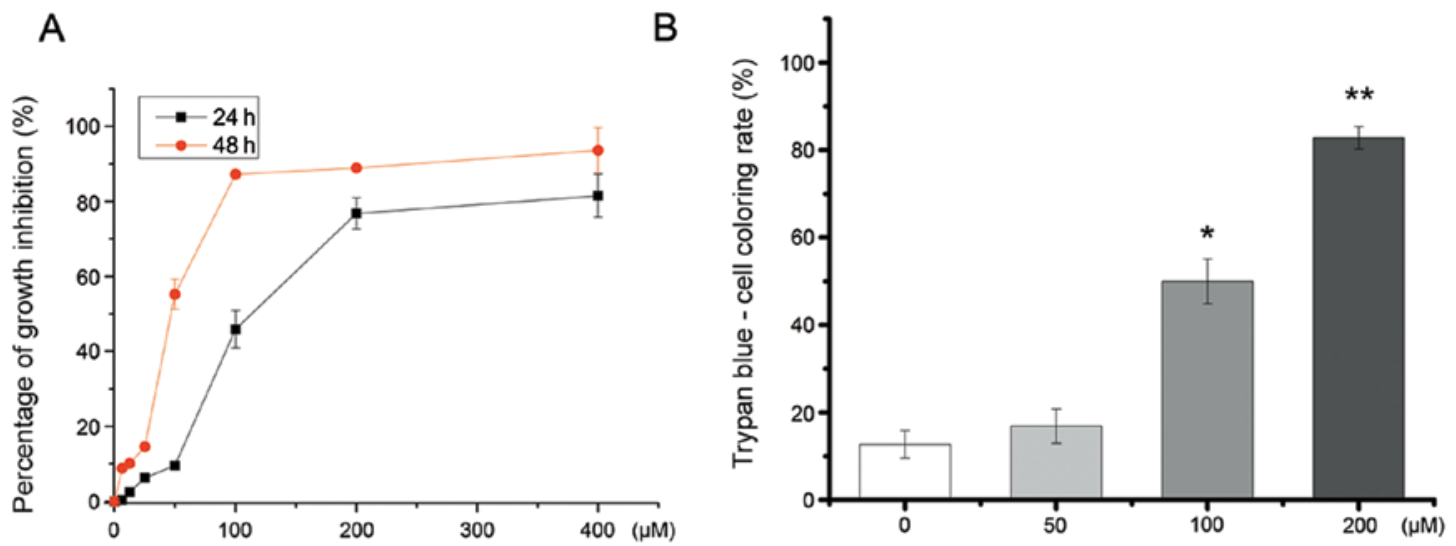

\section{C}
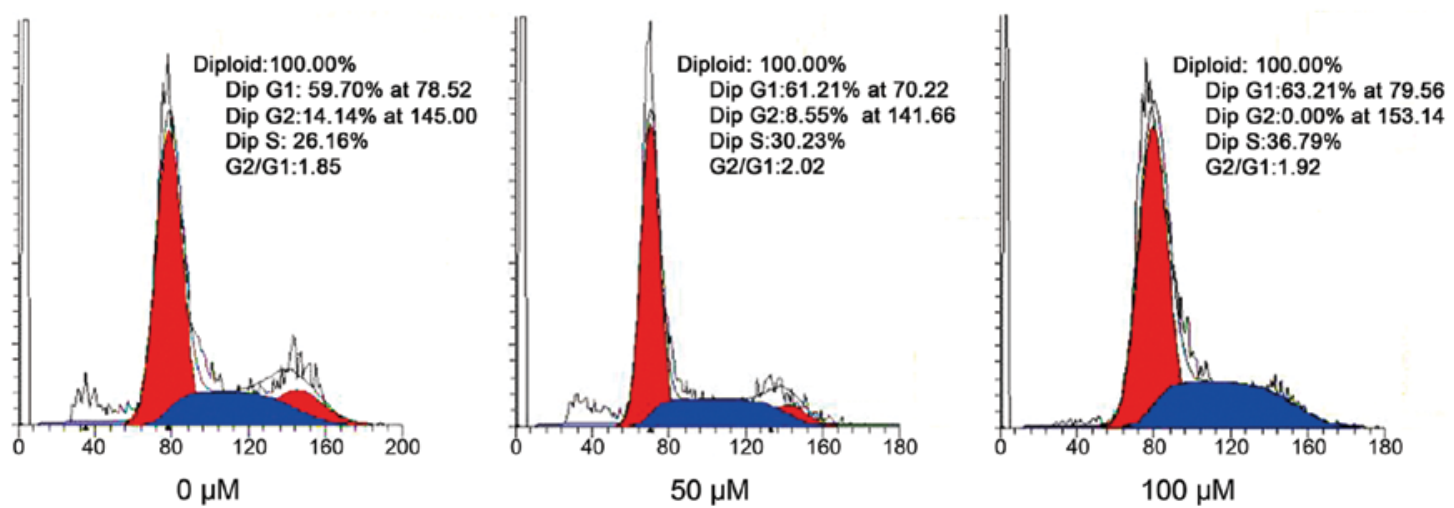

Figure 2. Inhibition of MGC803 cell growth and induction of apoptosis and G0/G1 cell cycle arrest by resveratrol. (A) Correlation of resveratrol drug doses and growth inhibition in MGC803 cells. y-axis, percentage of growth inhibition; x-axis, resveratrol concentration $(\mu \mathrm{M})$. (B) Cell viability assay: cells were incubated for $24 \mathrm{~h}$ and then stained with trypan blue. (C) Cell cycle analyses were performed by flow cytometry.

peroxidase (HRP)-conjugated antibody was purchased from Merck Millipore. The membranes were incubated with the appropriate HRP-conjugated anti-rabbit antibody (1:5,000; Cell Signaling Technology Inc.).

Statistical analysis. The obtained data were statistically analyzed and are presented as the mean \pm standard deviation (SD) of at least 3 independent experiments. Datasets with three or more groups were analyzed by one-way analysis of variance (ANOVA) or one-way ANOVA with repeated measures, and the last significant difference (LSD) post hoc test for multiple comparisons. Comparisons of two groups were analyzed using the Student's t-test. $\mathrm{P}<0.05$ was considered to indicate a statistically significant difference.

\section{Results}

Effects of resveratrol on the viability and cell cycle arrest of MGC803 cells. To investigate the effects of resveratrol on the growth of MGC803 cells, MGC803 cells were exposed to seven different concentrations of resveratrol $(6.25,12.5,25,50$, 100, 200 and $400 \mu \mathrm{M}$ ) for 24 and $48 \mathrm{~h}$. Resveratrol inhibited cell growth in a dose- and time-dependent manner (Fig. 2A). The half maximal inhibitory concentration $\left(\mathrm{IC}_{50}\right)$ of resveratrol for MGC803 cells was $\sim 29.0 \mu \mathrm{g} / \mathrm{ml}(127 \mu \mathrm{M})$ (Fig. 2A) at $24 \mathrm{~h}$ of incubation, and this concentration significantly increased at $48 \mathrm{~h}$ of incubation $(\mathrm{P}<0.05)$. The cell viability assay showed that resveratrol induced cell death in a dose-dependent manner at $24 \mathrm{~h}$ (Fig. 2B). Because resveratrol significantly inhibited the growth of MGC803 cells, we investigated the effects of resveratrol on cell cycle progression. Resveratrol treatment arrested MGC803 cells at the G0/G1 phase of the cell cycle, whereas cell cycle progression remained unchanged in the untreated cells (Fig. 2C). Treatment with $50 \mu \mathrm{M}$ resveratrol significantly increased the number of MGC803 cells arrested in the G0/G1 phase compared with the untreated MGC803 cells $(61.21 \pm 0.51$ vs. $59.70 \pm 0.36 \%, \mathrm{P}<0.05)$. Treatment with $100 \mu \mathrm{M}$ resveratrol treatment further increased the number of MGC803 cells arrested in the G0/G1 phase compared with the $50 \mu \mathrm{M}$ resveratrol treatment $(63.21 \pm 0.33 \%, \mathrm{P}<0.05)$. These data suggest that resveratrol at least partly inhibits the growth of GC cells by inducing $\mathrm{G} 0 / \mathrm{G} 1$ arrest.

Resveratrol inhibits the GSK3 $\beta$-dependent cyclin D1 signaling pathway in MGC803 cells. The GSK3 $\beta$-dependent cyclin D1 signaling pathway plays a critical role in the regulation of the G0/G1 transition of the cell cycle (16). We examined the effects of resveratrol on the expression of these two proteins. Cyclin D1 is a component of the core cell cycle machinery and is a key regulatory protein of the G1 phase of the cell cycle that allows the cell to progress to the $\mathrm{S}$ phase. The treatment of MGC803 cells with 100 and $200 \mu \mathrm{M}$ resveratrol substantially reduced the expression of cyclin D1 (Fig. 3A). The expression of cyclin D1 is known to be mediated by GSK3 $\beta$. Therefore, we 
A

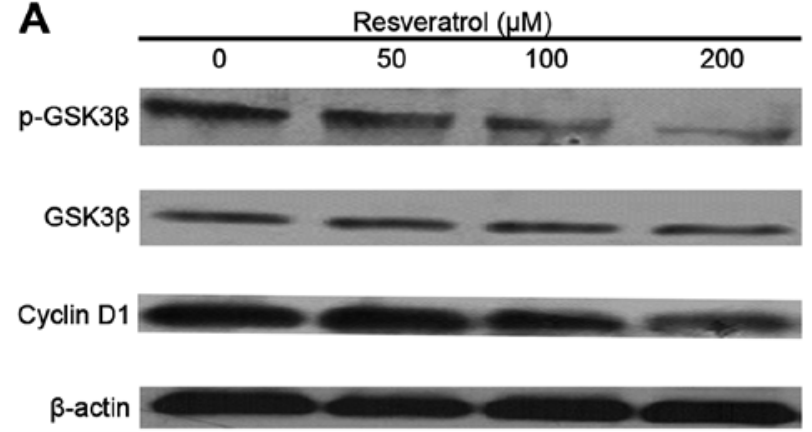

B

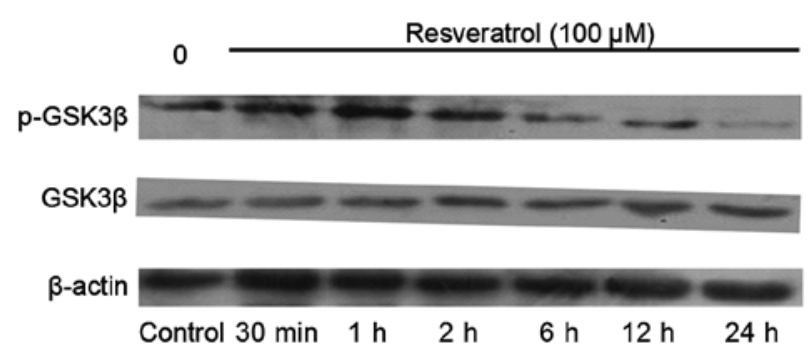

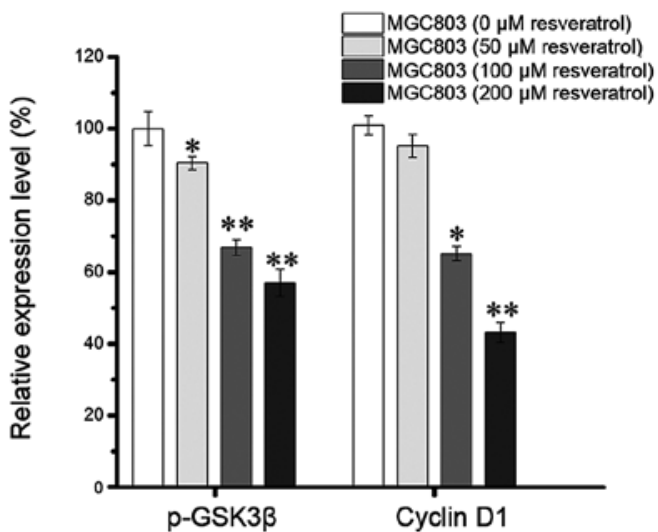

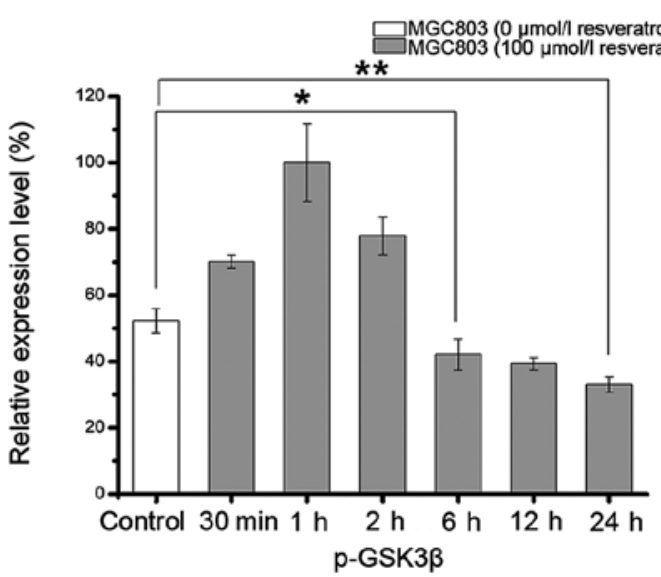

Figure 3. Resveratrol decreases the expression of phospho(p)-GSK3 $\beta$ and cyclin D1 in MGC803 cells. (A) Extracts of MGC803 cells treated with different concentrations of resveratrol were probed for p-GSK3 $\beta$ and cyclin D1 expression. p-GSK $3 \beta$ and cyclin D1 protein levels were quantified. ${ }^{*} \mathrm{P}<0.05$ or ${ }^{* *} \mathrm{P}<0.01$, compared with the control group. (B) p-GSK3 $\beta$ protein levels were detected in MGC803 cells at the indicated time points during treatment with resveratrol. Data were obtained from one of three individual experiments and indicate changes in expression. ${ }^{~} \mathrm{P}<0.05$ and ${ }^{* *} \mathrm{P}<0.01$ compared with the control group.

examined the involvement of GSK3 $\beta$ in the resveratrol-induced downregulation of cyclin D1 in MGC803 cells. Although the total protein level of GSK3 $\beta$ did not change, resveratrol markedly suppressed GSK $3 \beta$ phosphorylation within $24 \mathrm{~h}$ in a dose-dependent manner (Fig. 3A). Moreover, the protein expression of p-GSK3 $\beta$ was regulated in a time-dependent manner and significantly decreased after $6 \mathrm{~h}$ of incubation with resveratrol (Fig. 3B). These data suggest that resveratrol inhibits GSK $3 \beta$ and promotes the degradation of cyclin D1, leading to cell cycle arrest in the G1 phase.

Resveratrol inhibits PI3K/Akt signaling in MGC803 cells. Previous studies have shown that the phosphorylation and subsequent inactivation of GSK $3 \beta$ via the PI3K/Akt signaling pathway is important for tumor cell growth $(17,18)$. The PI3K/Akt signaling pathway is well defined and is directly associated with cell growth, proliferation and survival. After treatment for $24 \mathrm{~h}$, resveratrol inhibited the protein levels of $\mathrm{p}$-PI3K and p-Akt in a dose-dependent manner, as shown in Fig. 4A. Compared with the untreated cells, $100 \mu \mathrm{M}$ resveratrol inhibited the p-PI3K and p-Akt protein levels by 50.57 and $40.77 \%$, respectively and $200 \mu \mathrm{M}$ resveratrol inhibited the expression of these proteins by 64.56 and $61.24 \%$, respectively. We also found that the p-PI3K and p-Akt protein levels in MGC803 cells were decreased after $6 \mathrm{~h}$ of treatment with $100 \mu \mathrm{M}$ resveratrol (Fig. 4B). Taken together, these findings suggest that resveratrol inhibits GSK $3 \beta$ phosphorylation and degradation and decreases the protein level of cyclin D1 at least partly by inhibiting the PI3K-Akt pathway.

Resveratrol regulates PTEN activity to suppress the PI3K/Akt pathway. PTEN negatively regulates the activity of its upstream kinase, PI3K. PTEN blocks the action of PI3K by dephosphorylating the signaling lipid phosphatidylinositol $(3,4,5)$-trisphosphate (PIP3). Resveratrol was shown to decrease the protein level of p-PTEN (inactive) in a dose-dependent manner. This effect of resveratrol was apparent at concentrations ranging from 50 to $200 \mu \mathrm{M}$ and was maximized at $200 \mu \mathrm{M}$ (Fig. 5A). Subsequent investigations showed that $100 \mu \mathrm{M}$ resveratrol treatment resulted in the inactivation of PTEN in a time-dependent manner (Fig. 5B).

To determine the involvement of PTEN in the inhibition of PI3K/Akt signaling by resveratrol, RNA interference technology was adopted to silence endogenous PTEN expression. PTEN protein expression was significantly downregulated by PTEN-siRNA but not by the control siRNA treatment (Fig. 6). PTEN-siRNA treatment also reduced the protein level of p-PTEN. PTEN-siRNA also increased the activity of Akt kinase in the MGC803 cells (Fig. 6). Interestingly, resveratrol treatment after PTEN-siRNA transfection for $24 \mathrm{~h}$ slightly upregulated PTEN, suggesting that other factors are involved in the regulation of the PTEN protein level by resveratrol; however, this upregulation of PTEN was much weaker than that in cells that were not treated with PTEN-siRNA, and the 
A

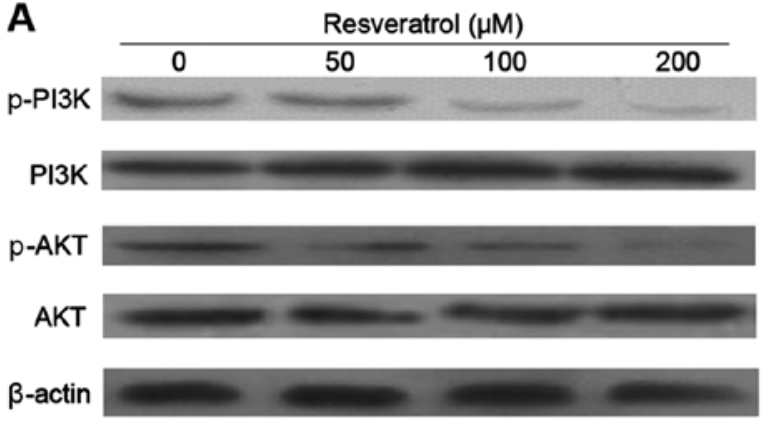

B

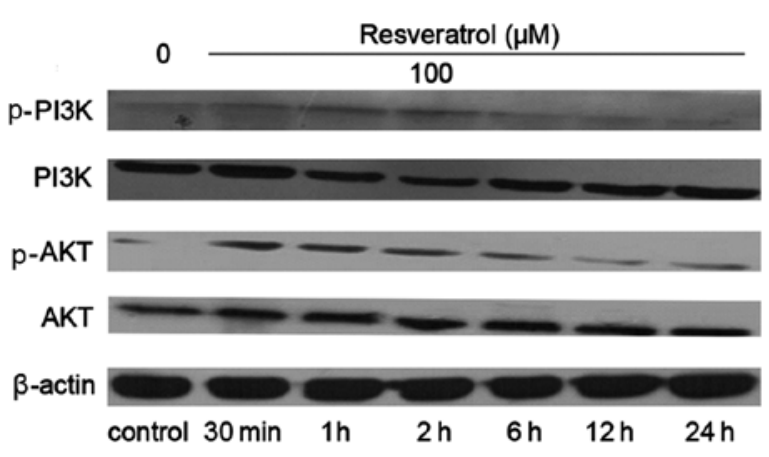

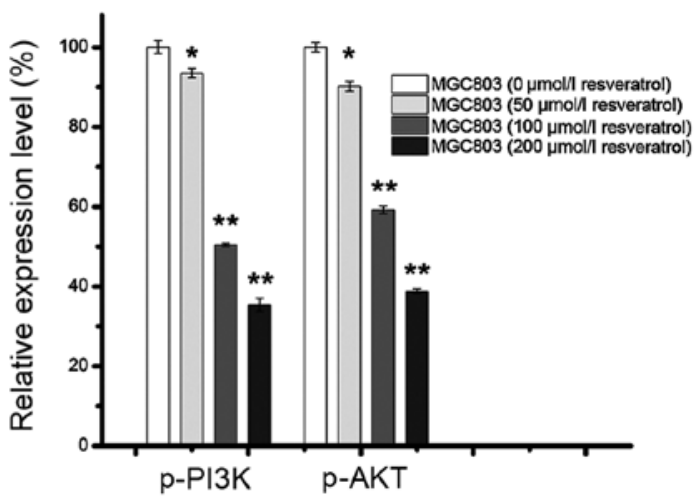

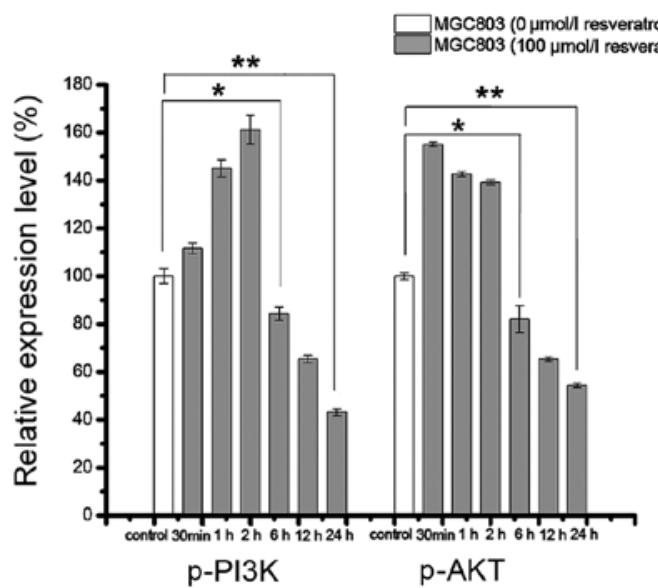

Figure 4. Resveratrol regulates the protein expression of phospho(p)-PI3K and p-Akt in MGC803 cells. (A) Extracts of MGC803 cells treated with 0, 50, 100 and $200 \mu \mathrm{M}$ resveratrol were probed for $\mathrm{p}-\mathrm{PI} 3 \mathrm{~K}$ and p-Akt protein expression. ${ }^{*} \mathrm{P}<0.05$ and ${ }^{* *} \mathrm{P}<0.01$ compared with the control group. (B) The protein levels of p-PI3K and p-Akt were detected in MGC803 cells at the indicated time points during resveratrol treatment. The p-Akt level was obtained from one of the three individual experiments and indicates a change in expression. ${ }^{*} \mathrm{P}<0.05$ and ${ }^{* *} \mathrm{P}<0.01$ compared with the control group.

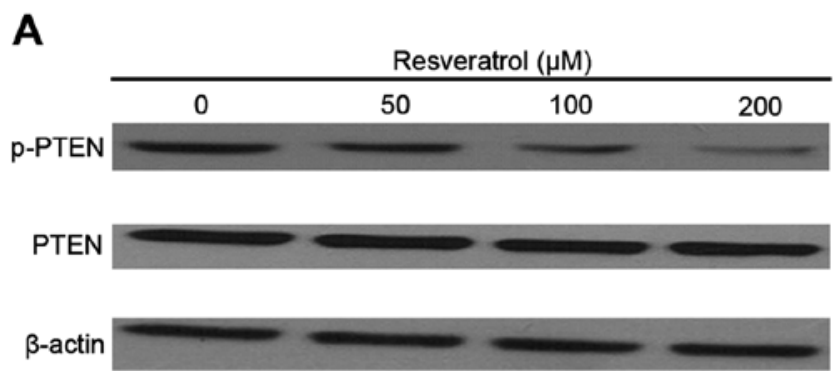

B
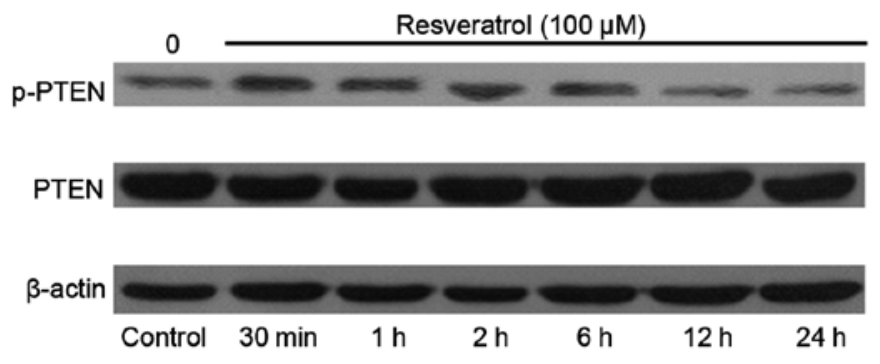
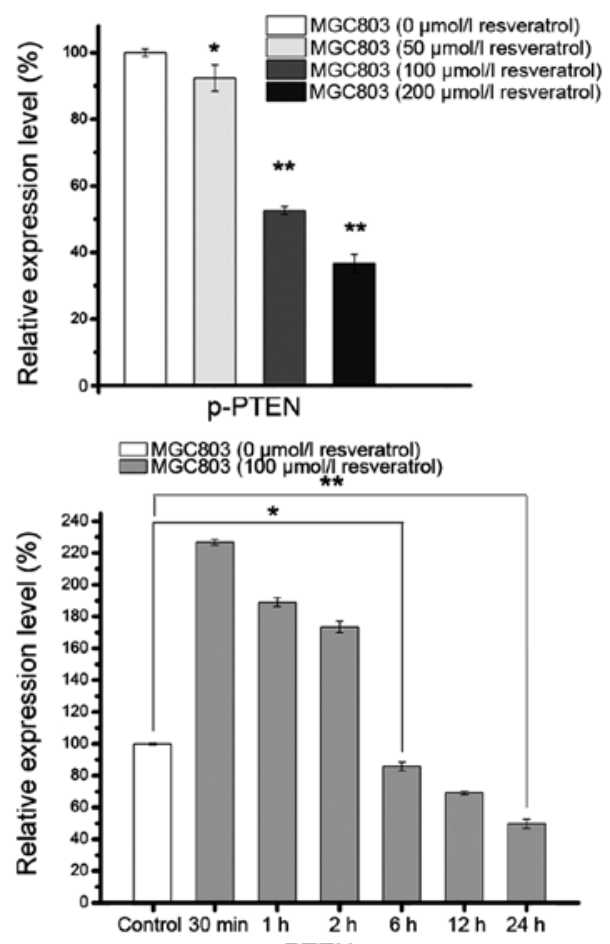

P-PTEN

Figure 5. Resveratrol regulates the protein expression of phospho(p)-PTEN in MGC803 cells. (A) Extracts of MGC803 cells treated with different concentrations of resveratrol were probed for $\mathrm{p}-\mathrm{PTEN}$ expression, and the p-PTEN protein levels were quantified. ${ }^{*} \mathrm{P}<0.05$ and ${ }^{* *} \mathrm{P}<0.01$ compared with the control group. (B) The p-PTEN protein levels were detected in MGC803 cells at the indicated time points during resveratrol treatment. The p-PTEN levels were obtained from one of three individual experiments and indicate a change in expression. ${ }^{*} \mathrm{P}<0.05$ and ${ }^{* *} \mathrm{P}<0.01$ compared with control group. 


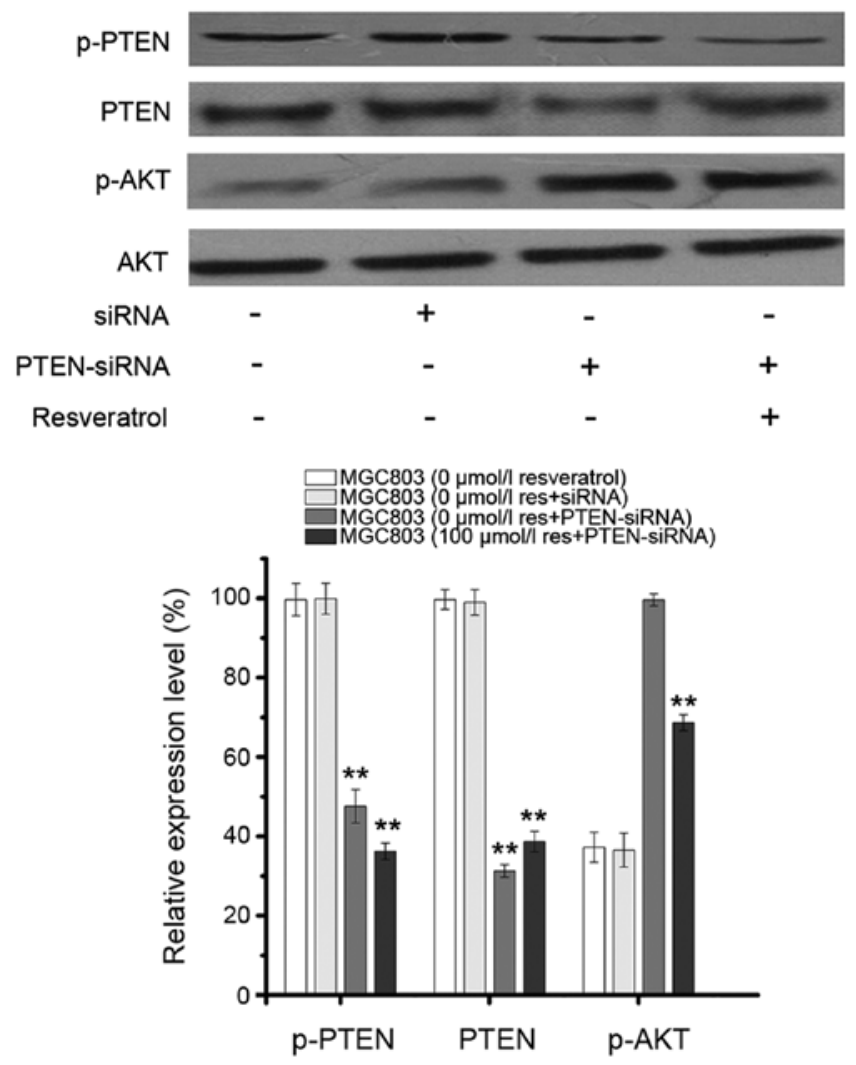

Figure 6. Knockdown of PTEN influences the inhibition of phospho(p)-Akt protein expression by resveratrol in MGC803 cells. After MGC803 cells were transfected with PTEN-siRNA or control siRNA, they were cultured for $24 \mathrm{~h}$ and then treated with resveratrol. PTEN, p-PTEN and p-Akt protein levels were quantified. ${ }^{*} \mathrm{P}<0.05$ and ${ }^{* *} \mathrm{P}<0.01$ compared with the control group.

protein level of p-Akt remained notably high (Fig. 6). These results showed that resveratrol inhibits the activity of the PI3K-Akt pathway by decreasing the protein level of p-PTEN in MGC803 cells.

\section{Discussion}

Despite aggressive treatment protocols that include chemotherapy, radiotherapy and surgery, the long-term survival of patients with localized GC has remained between 10 and $60 \%$ over the last two decades (19-22). Combination chemotherapy regimens are currently used as the primary treatment for this disease, but they have not significantly improved the clinical outcome. Therefore, the potential application of traditional Chinese medicine for the treatment of GC has garnered increasing interest (23-25). Many biologically active compounds used in traditional Chinese medicine show therapeutic efficacy in cancer patients and may consequently be used to develop first-line chemotherapies (26-29). Resveratrol, which is isolated from Polygonum cuspidatum, hellebore and grapes, inhibits the growth of many malignant tumor cells derived from the breast, colon, prostate, ovaries, and skin (30). The results presented here found that resveratrol inhibited the proliferation of human gastric MGC803 cells in vitro via G0/G1 arrest and robustly induced the apoptosis of MGC803 cells (Fig. 2).

We further evaluated the mechanism that regulates the apoptotic effect of resveratrol on MGC803 cells. Previous investigations have shown that cyclin D1 is a critical target of proliferative signals in the G1 phase and have strongly implicated it in carcinogenesis $(31,32)$. Furthermore, cyclin D1 proteolysis and subcellular localization are regulated by GSK3 $\beta$, which can be inactivated by phosphorylation (33-35). We herein showed that resveratrol dephosphorylated GSK3 $\beta$ and reduced the cyclin D1 level in a dose- and time-dependent manner (Fig. 3). Therefore, the GSK3 $\beta$-dependent catabolism of cyclin D1 may play an important role in the induction of cell cycle arrest by resveratrol and in its apoptotic effect on MGC803 cells.

The PI3K/Akt signaling pathway, an important signaling pathway involved in cell cycle progression, apoptosis and neoplastic transformation, is a major regulator of GSK3 $\beta$. Epidemiological and experimental studies have validated that this signaling pathway plays a key role in the initiation and maintenance of human tumors $(36,37)$. PI3K is a lipid kinase, and activated PI3Ks catalyze the formation of PIP3 from phosphatidylinositol 4,5-bisphosphate (PIP2) $(37,38)$. PIP3 is a second messenger that is essential for the translocation of Akt to the plasma membrane, where it is phosphorylated and activated. Activated Akt directly phosphorylates GSK3 $\beta$ and inhibits its kinase activity. Our study demonstrated that resveratrol reduced PI3K and Akt phosphorylation levels in MGC803 cells (Fig. 4), suggesting that resveratrol inhibits the PI3K/Akt signaling pathway to induce GSK3 $\beta$ dephosphorylation. It should be noted that p-GSK3 $\beta$ (Fig. 3B) and p-PI3K (Fig. 4B) were initially increased and then finally decreased. The increase in p-GSK3 $\beta$ and $\mathrm{p}-\mathrm{PI} 3 \mathrm{~K}$ at an early stage may be due to the protective adaptive response of tumor cells to resveratrol treatment. Actually, the decrease in p-GSK3 $\beta$ and p-PI3K at a later stage represents the rapid effect of resveratrol. Further experiments should be used to exploit this special expression pattern.

PTEN negatively regulates the PI3K/Akt signaling pathway, which plays an important role in the modulation of cell cycle progression (39-41). PTEN dephosphorylates PIP3 and negatively regulates the PI $3 \mathrm{~K}$ signaling pathway. In the present study, PTEN phosphorylation (inactive) was significantly decreased in the MGC803 cells exposed to resveratrol. Furthermore, we used PTEN-siRNA to inhibit the expression of PTEN protein and demonstrated that resveratrol did not decrease the phosphorylation level of Akt in MGC803 cells (Fig. 6). Therefore, the targeting of PTEN by resveratrol is also critical for the induction of cell cycle arrest and apoptosis in MGC803 cells.

In conclusion, resveratrol strongly inhibited GC cells in vitro. Specifically, it inhibited cell proliferation and induced apoptosis and cell cycle arrest. Furthermore, the status of the PI3K/PTEN/Akt pathway in GC cells significantly affected the efficacy of resveratrol, and resveratrol triggered the dephosphorylation of GSK3 $\beta$, which resulted in cyclin D1 degradation and eventually, cell cycle arrest and apoptosis. These findings suggest that resveratrol is a promising agent for the treatment of GC.

\section{Acknowledgements}

The present study was supported by Shanghai Natural Science Foundation of China (13ZR1434300) and Shanghai Science and Technology Committee Foundation of China (13495810300). 


\section{References}

1. Ferlay J, Soerjomataram I, Dikshit R, Eser S, Mathers C, Rebelo M, Parkin DM, Forman D and Bray F: Cancer incidence and mortality worldwide: Sources, methods and major patterns in GLOBOCAN 2012. Int J Cancer 136: 359-386, 2015.

2. Bang YJ, Kim YW, Yang HK, Chung HC, Park YK, Lee KH, Lee KW, Kim YH, Noh SI, Cho JY, et al; CLASSIC trial investigators: Adjuvant capecitabine and oxaliplatin for gastric cancer after D2 gastrectomy (CLASSIC): A phase 3 open-label, randomised controlled trial. Lancet 379: 315-321, 2012.

3. Sasako M, Sakuramoto S, Katai H, Kinoshita T, Furukawa H, Yamaguchi T, Nashimoto A, Fujii M, Nakajima T and Ohashi Y: Five-year outcomes of a randomized phase III trial comparing adjuvant chemotherapy with S-1 versus surgery alone in stage II or III gastric cancer. J Clin Oncol 29: 4387-4393, 2011.

4. Aggarwal BB, Bhardwaj A, Aggarwal RS, Seeram NP, Shishodia S and Takada Y: Role of resveratrol in prevention and therapy of cancer: Preclinical and clinical studies. Anticancer Res 24: 2783-2840, 2004

5. Piotrowska H, Kucinska M and Murias M: Biological activity of piceatannol: Leaving the shadow of resveratrol. Mutat Res 750: 60-82, 2012.

6. Kucinska M, Piotrowska H, Luczak MW, Mikula-Pietrasik J, Ksiazek K, Wozniak M, Wierzchowski M, Dudka J, Jäger W and Murias M: Effects of hydroxylated resveratrol analogs on oxidative stress and cancer cells death in human acute T cell leukemia cell line: Prooxidative potential of hydroxylated resveratrol analogs. Chem Biol Interact 209: 96-110, 2014.

7. Kim JE, Lee JI, Jin DH, Lee WJ, Park GB, Kim S, Kim YS, Wu TC, Hur DY and Kim D: Sequential treatment of HPV E6 and E7-expressing TC-1 cells with bortezomib and celecoxib promotes apoptosis through p-p38 MAPK-mediated downregulation of cyclin D1 and CDK2. Oncol Rep 31: 2429-2437, 2014.

8. Zhang J, Wei J, Lu J, Tong Z, Liao B, Yu B, Zheng F, Huang X, Chen Z, Fang Y, et al: Overexpression of Rab25 contributes to metastasis of bladder cancer through induction of epithelialmesenchymal transition and activation of Akt/GSK-3 $\beta /$ Snail signaling. Carcinogenesis 34: 2401-2408, 2013.

9. Mirzoeva OK, Hann B, Hom YK, Debnath J, Aftab D, Shokat K and Korn WM: Autophagy suppression promotes apoptotic cell death in response to inhibition of the PI3K-mTOR pathway in pancreatic adenocarcinoma. J Mol Med Berl 89: 877-889, 2011.

10. Yan-nan B, Zhao-yan Y, Li-xi L, jiang Y, Qing-jie X and Yong Z MicroRNA-21 accelerates hepatocyte proliferation in vitro via PI3K/Akt signaling by targeting PTEN. Biochem Biophys Res Commun 443: 802-807, 2014.

11. Sansal I and Sellers WR: The biology and clinical relevance of the PTEN tumor suppressor pathway. J Clin Oncol 22: 2954-2963, 2004.

12. Maehama T and Dixon JE: The tumor suppressor,PTEN/MMAC1, dephosphorylates the lipid second messenger, phosphatidylinositol 3,4,5-trisphosphate. J Biol Chem 273: 13375-13378, 1998.

13. Lu Y, Lin YZ, LaPushin R, Cuevas B, Fang X, Yu SX, Davies MA, Khan H, Furui T, Mao M, et al: The PTEN/MMAC1/TEP tumor suppressor gene decreases cell growth and induces apoptosis and anoikis in breast cancer cells. Oncogene 18: 7034-7045, 1999.

14. Weng L, Brown J and Eng C: PTEN induces apoptosis and cell cycle arrest through phosphoinositol-3-kinase/Akt-dependent and -independent pathways. Hum Mol Genet 10: 237-242, 2001.

15. Louis KS and Siegel AC: Cell viability analysis using trypan blue: Manual and automated methods. Methods Mol Biol 740: 7-12, 2011.

16. Yu XJ, Han QB, Wen ZS, Ma L, Gao J and Zhou GB: Gambogenic acid induces G1 arrest via GSK3 $\beta$-dependent cyclin D1 degradation and triggers autophagy in lung cancer cells. Cancer Lett 322: 185-194, 2012.

17. Riles WL, Erickson J, Nayyar S, Atten MJ, Attar BM and Holian O: Resveratrol engages selective apoptotic signals in gastric adenocarcinoma cells. World J Gastroenterol 12: 5628-5634, 2006.

18. Yang W, Zhang Y, Li Y, Wu Z and Zhu D: Myostatin induces cyclin D1 degradation to cause cell cycle arrest through a phosphatidylinositol 3-kinase/AKT/GSK-3 beta pathway and is antagonized by insulin-like growth factor 1 . J Biol Chem 282: 3799-3808, 2007.

19. Coupland VH,Allum W, Blazeby JM,Mendall MA,Hardwick RH, Linklater KM, Møller H and Davies EA: Incidence and survival of oesophageal and gastric cancer in England between 1998 and 2007, a population-based study. BMC Cancer 12: 11, 2012.
20. Kunz PL, Gubens M, Fisher GA, Ford JM, Lichtensztajn DY and Clarke CA: Long-term survivors of gastric cancer: A California population-based study. J Clin Oncol 30: 3507-3515, 2012.

21. Zheng L, Wu C, Xi P, Zhu M, Zhang L, Chen S, Li X, Gu J and Zheng Y: The survival and the long-term trends of patients with gastric cancer in Shanghai, China. BMC Cancer 14: 300, 2014.

22. Ito $Y$, Nakayama T, Miyashiro I, Ioka A and Tsukuma H: Conditional survival for longer-term survivors from 2000-2004 using population-based cancer registry data in Osaka, Japan. BMC Cancer 13: 304, 2013.

23. Ge J, Liu Y, Li Q, Guo X, Gu L, Ma ZG and Zhu YP: Resveratrol induces apoptosis and autophagy in T-cell acute lymphoblastic leukemia cells by inhibiting Akt/mTOR and activating p38-MAPK. Biomed Environ Sci 26: 902-911, 2013.

24. Meng LY, Liu HR, Shen Y, Yu YQ and Tao X: Cochinchina momordica seed extract induces $\mathrm{G} 2 / \mathrm{M}$ arrest and apoptosis in human breast cancer MDA-MB-231 cells by modulating the PI3K/Akt pathway. Asian Pac J Cancer Prev 12: 3483-3488, 2011.

25. Zhang F, Liu J and Shi JS: Anti-inflammatory activities of resveratrol in the brain: Role of resveratrol in microglial activation. Eur J Pharmacol 636: 1-7, 2010.

26. Orsu P, Murthy BV and Akula A: Cerebroprotective potential of resveratrol through anti-oxidant and anti-inflammatory mechanisms in rats. J Neural Transm 120: 1217-1223, 2013.

27. Tomé-Carneiro J, Larrosa M, Yáñez-Gascón MJ, Dávalos A, Gil-Zamorano J, Gonzálvez M, García-Almagro FJ, Ruiz Ros JA, Tomás-Barberán FA, Espín JC, et al: One-year supplementation with a grape extract containing resveratrol modulates inflammatory-related microRNAs and cytokines expression in peripheral blood mononuclear cells of type 2 diabetes and hypertensive patients with coronary artery disease. Pharmacol Res 72: 69-82, 2013.

28. Kauffmann-Zeh A, Rodriguez-Viciana P, Ulrich E, Gilbert C, Coffer P, Downward J and Evan G: Suppression of c-Myc-induced apoptosis by Ras signalling through PI(3)K and PKB. Nature 385: 544-548, 1997.

29. Liang J and Slingerland JM: Multiple roles of the PI3K/PKB (Akt) pathway in cell cycle progression. Cell Cycle 2: 339-345, 2003.

30. Ji Q, Liu X, Fu X, Zhang L, Sui H, Zhou L, Sun J, Cai J, Qin J, Ren J, et al: Resveratrol inhibits invasion and metastasis of colorectal cancer cells via MALAT 1 mediated Wnt $/ \beta$-catenin signal pathway. PLoS One 8: e78700, 2013.

31. Baldin V, Lukas J, Marcote MJ, Pagano M and Draetta G: Cyclin D1 is a nuclear protein required for cell cycle progression in G1. Genes Dev 7: 812-821, 1993.

32. Choi YJ, Li X, Hydbring P, Sanda T, Stefano J, Christie AL, Signoretti S, Look AT, Kung AL, von Boehmer H, et al: The requirement for cyclin $\mathrm{D}$ function in tumor maintenance. Cancer Cell 22: 438-451, 2012.

33. Chen XL, Ren KH, He HW and Shao RG: Involvement of $\mathrm{PI} 3 \mathrm{~K} / \mathrm{KT} / \mathrm{GSK} 3$ beta pathway in tetrandrine-induced G1 arrest and apoptosis. Cancer Biol Ther 7: 1073-1078, 2008.

34. Pontano LL and Diehl JA: DNA damage-dependent cyclin D1 proteolysis: GSK3beta holds the smoking gun. Cell Cycle 8: 824-827, 2009.

35. Ashford AL, Oxley D, Kettle J, Hudson K, Guichard S, Cook SJ and Lochhead PA: A novel DYRK1B inhibitor AZ191 demonstrates that DYRK1B acts independently of GSK $3 \beta$ to phosphorylate cyclin D1 at Thr(286), not Thr(288). Biochem J 457: 43-56, 2014.

36. Garcia-Echeverria $C$ and Sellers WR: Drug discovery approaches targeting the PI3K/Akt pathway in cancer. Oncogene 27: 5511-5526, 2008.

37. Osaki M, Oshimura M and Ito H: PI3K-Akt pathway: Its functions and alterations in human cancer. Apoptosis 9: 667-676, 2004.

38. Fresno Vara JA, Casado E, de Castro J, Cejas P, Belda-Iniesta C and González-Barón M: PI3K/Akt signalling pathway and cancer. Cancer Treat Rev 30: 193-204, 2004.

39. Weng LP, Brown JL and Eng C: PTEN coordinates G(1) arrest by down-regulating cyclin D1 via its protein phosphatase activity and up-regulating p27 via its lipid phosphatase activity in a breast cancer model. Hum Mol Genet 10: 599-604, 2001.

40. Huang W, Chang HY, Fei T, Wu H and Chen YG: GSK3 beta mediates suppression of cyclin D2 expression by tumor suppressor PTEN. Oncogene 26: 2471-2482, 2007.

41. Zhao H, Yang J, Fan T, Li S and Ren X: RhoE functions as a tumor suppressor in esophageal squamous cell carcinoma and modulates the PTEN/PI3K/Akt signaling pathway. Tumour Biol 33: 1363-1374, 2012. 